\title{
21. LOS OBSTÁCULOS A LA REFORMA DEL SENADO: FALSOS Y VERDADEROS
}

\author{
MANUEL MARTÍNEZ SOSPEDRA \\ Profesor Titular de Derecho Constitucional \\ Profesor Libertades Públicas. S. Pablo-CEU
}


SUMARIO

INTRODUCCIÓN.-I. LOS OBSTÁCULOS FALSOS.-a) El adecuado funcionamiento del Senado como Cámara de Segunda Lectura. b) El (posible) adecuado funcionamiento del Senado como Cámara Territorial. c) La dificultad de establecer la composición del Senado como Cámara Territorial. d) La dificultad (técnica) para obtener el consenso sobre la reforma del Senado entre los partidos nacionales. e) La inviabilidad política de un Senado cuasi-federal: 1) El carácter homogeneizador y uniforme de la representación y las competencias de las Comunidades Autónomas. 2) La dilución de la especificidad nacionalitaria. 3) El veto de los partidos nacionalistas moderados. II. Los OBSTÁCULOS VERDADEROS.-a) La defectuosa comprensión de la naturaleza de la reforma constitucional. b) La indefinición de la reforma. c) El temor al desmandamiento del proceso de reforma. d) La ausencia de voluntad política: 1) Un Senado cómodo para el Gobierno. 2) Un Senado cómodo para el Congreso. 3) Un Senado cómodo para las cúpulas partidistas. e) La hostilidad a la potenciación del Senado. NOTA BIBLIOGRÁFICA. 


\title{
21. LOS OBSTÁCULOS A LA REFORMA DEL SENADO: FALSOS Y VERDADEROS
}

\author{
POR \\ MANUEL MARTÍNEZ SOSPEDRA \\ Profesor Titular de Derecho Constitucional \\ Profesor de Libertades Públicas. S. Pablo-CEU
}

INTRODUCCIÓN

La cuestión de la reforma del Senado es casi tan vieja como la propia versión actual de la Cámara Alta, existiendo en la doctrina una unanimidad virtual en lo insatisfactorio de su régimen constitucional actual y en su inadaptación a la estructura del Estado que ha ido naciendo y desarrollándose al amparo del Título VIII de la Constitución desde 1980. Tan es así que aun durante la primera Legislatura uno de los ponentes del texto de 1978, HERRERO DE MIÑóN, calificaba en términos durísimos la regulación del Senado constitucional y planteaba la necesidad de su reforma, y que uno de los más lúcidos estudiosos de la reforma constitucional proponía, hace más de seis años, la necesidad de la reforma de la Cámara Alta criticando la pasividad del Parlamento en la cuestión, curiosamente en un trabajo editado por el propio Parlamento.

Mas, si encontrar en la doctrina un tratamiento favorable del Senado constitucional, fuera del trabajo de GARCÍA-ESCUDERO y PENDAS, es tarea de cumplimiento imposible, si la presente regulación de la Cámara despierta el escepticismo de los cuadros dirigentes de los partidos del arco constitucional, si la reforma en este punto ha sido demandada públicamente al menos por tres ponentes constitucionales y dicha demanda ha obtenido amplio respaldo en ese actor político de primera magnitud que es entre nosotros la prensa escrita, la tozuda realidad política parece em- 
peñada en demostrarnos a todos que, pese a quien pese, el Senado español parece condenado a padecer una mala salud de hierro.

Si eso es así se debe indudablemente a que, frente a los propósitos y propuestas de reforma, que no han faltado en la doctrina, de PUNSET a FERNÁDEZ SEGADO, pasando por el que suscribe, se han elevado obstáculos considerables, pues de otro modo sería inexplicable que se diera la realidad presente. La presente nota, que ni puede pretender ni pretende otra cosa que plantear el tema, se dirige a espigar, de entre la multiplicidad de obstáculos alegados, cuáles son pertinentes y cuáles no lo son a fin de contribuir a clarificar un debate, afortunadamente en curso, del que puede depender el futuro inmediato de una importante pieza del sistema de gobierno nacional.

Resulta obvio que el autor milita entre quienes estiman que la reforma de la Ley Fundamental en este punto es necesaria, y lleva siéndolo desde hace años.Ya en 1980 él mismo planteó la inadecuación del Senado Constitucional al modelo de Estado insinuado por la Ley Fundamental y hace no mucho publicó una monografía sobre el tema avanzando propuestas razonadas $y$ concretas $y$, si la experiencia es un grado, el haber servido en la Cámara Alta durante tres años y haber tenido algo que ver en los trabajos preparatorios y preliminares de la reforma del Reglamento del Senado, ese grado ha servido, en mi caso al menos, para confirmar y aún reforzar las opiniones anteriormente sostenidas. Pero si la necesidad justifica por sí sola una toma de postura, para que la misma tenga posibilidad de transformarse en actos, si la reforma tiene efectivamente que producirse, es necesario, además, que exista oportunidad. $Y$ en esas estamos. Cuando la ratificación del Tratado de Unión Europea va a exigir reforma constitucional afectante a la titularidad y ejercicio de un derecho fundamental o, al menos, al Capítulo I del Título I de la Constitución, no me parece desencaminado afirmar que estamos abocados a una coyuntura en la que la necesidad puede tener la oportunidad que necesita para que la satisfacción de la misma se materialice.

La cuestión, así planteada, tiene una implicación política obvia en un momento en que parece que, por enésima y parece que definitiva vez, tiene trazas de salir adelante una reforma del funcionamiento de la Cámara Alta, orientada a su "territorialización» mediante el recurso a una reforma manipulativa del Reglamento del Senado animada por una voluntad de mutación constitucional. En otras palabras, en un momento en el que parece, de nuevo, que existen posibilidades serias de instrumentar algunas de la medidas sugeridas, tanto en sede doctrinal como en sede política, destinadas a procurar una «optimización» del Senado Constitucional. He escrito "algunas», porque de las avanzadas tanto por la doctrina, cuan- 
to por algunas fuerzas políticas con representación parlamentaria, sólo una parte parecen en trance de llegar a puerto. Lo hecho, con una dilación no inferior a los cinco años me parece que abona más bien la tesis, sostenida por mí en otra sede, según la cual los costes de una reforma manipulativa subconstitucional no son significativamente menores de los propios de la reforma constitucional. $Y$ su rendimiento previsible es significativamente menor, mucho menor, que el de la reforma. Hasta el punto de que uno de los argumentos esenciales utilizados en su defensa consiste, en román paladino, en plantear la reforma del Reglamento de la Cámara como un compromiso dilatorio.

\section{LOS OBSTÁCULOS FALSOS}

"Obstáculo Falso" en el sentido de esta nota es aquel que, siendo alegado como motivación para sostener el carácter no necesario, o inconveniente, o no oportuno, de realizar una reforma constitucional afectante al Senado, o bien carece de entidad suficiente para ello, o bien carece de la necesaria base en la realidad como para ser considerado razonablemente como circunstancia dificultativa o impeditiva. Siempre a juicio del autor. Aunque tales obstáculos son susceptibles de recibir vestiduras diversas me parece razonable sostener que los mismos son reducibles a cuatro: en primer lugar la tesis del funcionamiento satisfactorio del Senado Constitucional, que reviste dos formas, según se afirme tal propiedad del Senado en cuanto Cámara de segunda deliberación, o como Cámara Territorial; en segundo lugar las dificultades que plantea la composición de un posible Senado Territorial; en tercer lugar, la dificultad de obtener el consenso entre los partidos parlamentarios de ámbito nacional; finalmente el de la inviabilidad política de un Senado Territorial congruente con la estructura del Estado realmente existente en razón de la dificultad de obtener para ello el consenso de las minorías nacionalistas.

\section{a) El adecuado funcionamiento del Senado como Cámara de Segunda Lectura}

Reconozco que el presente es. al menos en el terreno doctrinal, el argumento más fuerte esgrimible en defensa del Senado Constitucional. Porque si hay algo en que casi todos los críticos del mismo y sus defensores están de acuerdo, si hay un punto en el que algo parecido a un consenso mayoritario es de posible formación, en cuanto al Senado afecta, es 
precisamente éste. En efecto, la mayor parte de la doctrina ha venido en convenir que el funcionamiento del Senado como Cámara de Segunda Deliberación de los proyectos de Ley aprobados por el Congreso merece una calificación global positiva. Tal juicio se asienta en dos afirmaciones mayoritariamente aceptadas: que la segunda lectura en la Cámara Alta al prolongar el iter legislativo amplia las posibilidades de negociación y consenso sobre las orientaciones y políticas instrumentadas en los proyectos legislativos, y, en consecuencia, facilita el acuerdo, y que la segunda deliberación ha permitido en no pocos casos corregir los errores, tanto técnicos como políticos, de los textos votados por el Congreso. En este sentido la práctica del voto definitivo favorable del Congreso sobre el texto de las enmiendas adoptadas por el Senado, que constituye una regla con escasas excepciones, es bien ilustrativa, y acredita que la influencia de la Cámara Alta sobre la legislación no puede calificarse de desdeñable.

Sin entrar ahora en la cuestión de si esa posición favorable que el Senado constitucional alcanza a la hora de enjuiciar su función en el proceso legiferente se logra "gracias a" su régimen constitucional o se obtiene, al menos en parte, "a pesar de" ese mismo régimen el argumento en cuestión es, para el tema que nos ocupa, irrelevante. Porque la cuestión de reforma del Senado no gira en torno a la posición que el mismo ocupa en el proceso de producción legislativa - que aún así es manifiestamente mejorable - la cuestión de la reforma de la Cámara Alta gira en torno a la estructura estatal realmente existente y a sus exigencias, y aquí el argumento en cuestión -y el obstáculo que el mismo puede suponer- son perfectamente prescindibles. La cuestión de la reforma del Senado no es lo que la Cámara Alta hace, sino más bien lo que, siendo necesario, está imposibilitado de hacer.

\section{b) El (posible) adecuado funcionamiento del Senado como Cámara Territorial}

A primera vista puede parecer sorprendente esa afirmación, porque si en algo es unánime la doctrina, y la opinión pública, es que el Senado español no es una Cámara Territorial, ni por su representación, ni por sus poderes, ni por sus funciones. Parece, pues, que no tiene sentido plantearse y rechazar como erróneo un argumento que nadie defiende. Pero es que la realidad no es ésa. La realidad señala más bien que hay posiciones sostenidas en torno a la cuestión que reposan sobre el presupuesto de que el Senado tal y como viene diseñado por la Constitución encierra la potencialidad de una Cámara Territorial satisfactoria, que no hay nada en el diseño constitucional que impida que el Senado en ella diseñado satisfaga 
las desatendidas exigencias de coordinación, participación e integración que dimanan de la estructura del Estado, y que si el Senado constitucional no funciona como tal Cámara Territorial el mal se halla en los usos y en las normas infraconstitucionales, por lo que los adecuados cambios en unos y otras permitirían que se realizasen plenamente las potencialidades insitas en el diseño de la Ley Fundamental.

Más claro, el proyecto de optimización del Senado Constitucional mediante la creación de convenciones constitucionales y la reforma del Reglamento tiene por presupuesto necesario el argumento que se acaba de exponer.Y sin él carece de sentido como propuesta sustantiva.

En efecto, las medidas sugeridas para esa operación de optimización, y que van desde la exigencia de condiciones de elegibilidad "territoriales" y el cambio en la política de personal de los partidos, hasta la creación de la "Gran Comisión de Autonomías", pasando por los retoques en el procedimiento legislativo tienen sentido cuando y en la medida en que se piense seriamente que el diseño constitucional del Senado encierra en sí mismo posibilidades serias de satisfacer aquellas exigencias del Estado complejo de que más arriba se habló. La reforma manipulativa -en la medida en que es un objetivo en sí mismo y no una operación preparatoria o dilatoria- presume que el Senado actual, con su composición actual y sus poderes actuales, puede desarrollar funciones diferentes $y$ atraer un personal distinto y políticamente mas cualificado que el actual. Con independencia de que algunas de las propuestas avanzadas, en tanto en cuanto comportan la asignación de poderes y funciones sustancialmente distintas a las actuales y la modificación de la composición de los miembros de un órgano constitucional por normas infraconstitucionales es contradictoria con la noción misma de "órgano constitucional" y supone en unos casos bordear y en otros caer en infracción de la Constitución, permanece en pie el hecho de que el proyecto se asienta sobre un banco de arena. Con el agravante de que todo el mundo sabe que el rey se pasea en paños menores, incluido por supuesto el rey.

Considérese que lo que se nos pide es que creamos que el Senado actual, con sus cuatro quintas partes de senadores de extracción provincial, va a ser, o puede ser, un instrumento eficaz a fin de integrar a las Comunidades Autónomas en los procesos de formación de voluntad del Estado, dándoles una participación eficaz en la determinación de la política nacional. Y ello sin incrementar sustancialmente los poderes de la Cámara. O que se puede cambiar la dinámica de la política de personal de los partidos con apelaciones voluntaristas - eso sí inmejorablemente intencionadas-a fin de mejorar la calidad e importancia política media de los candidatos al Senado sin darle a éste los mayores poderes que harían racional 
tal cambio de política desde la perspectiva de los partidos.Y asi sucesivamente.

Por lo demás, ni quienes desde la doctrina han propuesto el proyecto, ni quienes desde las fuerzas políticas parlamentarias lo impulsan tienen esa percepción del proyecto mismo. Nadie ha pensado, ni concibe, la optimización del Senado constitucional como una propuesta sustantiva. Más bien viene entendida como un ersatz que para unos permite dilatar en el tiempo el enfrentamiento con el problema de fondo, o como un expediente provisional dotado de la virtualidad del experimento, lo que, a no dudarlo, puede ser útil a corto plazo, pero tiene un valor discutible $y$ una validez temporal limitada.

A la postre tiene razón TOYNBEE: aplazar la respuesta a los retos de la realidad no tiene a la larga otra consecuencia que hacer progresivamente más costoso afrontar el reto inevitable.

\section{c) La dificultad (técnica) de establecer la composición del Senado como Cámara Territorial}

Es, sin duda alguna, el más débil de los argumentos obstativos, y las razones resultan obvias: de un lado existe una amplia experiencia en punto al problema de la composición y elección de una asamblea territorial adaptada a nuestras necesidades, incluso en sede doctrinal existen propuestas detalladas y concretas que permiten resolver fácilmente el problema si existe la voluntad política de hacerlo. Por este lado no queda más que discutir si es o no conveniente que exista en el Senado de las Autonomías un cupo de senadores capaces de actuar como moderadores - según la vieja idea de OLLERO- $y$, en caso positivo precisar su mandato (igual, mayor o vitalicio) y el método de elección (cooptación como en Bélgica, designación gubernamental o real, elección indirecta o directa, etcétera). Ni siquiera es problema serio el establecer las facultades, puesto que esa es cuestión cuyo fondo viene decidido en la proyectada reforma del Reglamento del Senado: una posición más fuerte en las "leyes territoriales".

De hecho, el argumento en cuestión es muy poco más que un acompañamiento coreográfico de los anteriores, y más sólidos, y de los siguientes, y más importantes. 


\section{d) La dificultad para obtener el consenso sobre la reforrna del Senado entre los partidos nacionales}

El presente es un argumento reversible: lo mismo se puede aplicar a la reforma constitucional que a la optimización del Senado constitucional, ya que no hace sino reflejar la división de opiniones existente. Si dejamos de lado las fórmulas rituales de valor poco menos que litúrgico, la situación puede ser expresada como sigue: IU se ha pronunciado abierta y oficialmente en favor de la reforma constitucional, en el PP es ampliamente mayoritaria y cuasioficial la misma tesis, en el caso del PSOE la postura oficial es contraria y favorable a la optimización del Senado constitucional, pero en el valor entendido de que esa opción es transitoria, hasta tanto se den las condiciones políticas que hagan viable la reforma - que no se explicita cuáles son- $y$, como se ha señalado, experimental, es decir, es una postura de "si, pero" o de "todavía no y entre tanto veamos", no hay pues hostilidad de fondo. Finalmente en el caso de CDS la posición oficial ha sido contraria por la influencia personal del señor Suárez, y en la actualidad carece de posición definida, si bien, por inercia, se mantiene la tesis de la optimización del Senado constitucional, entre otras razones porque la estructura de la proyectada reforma del Reglamento tiene una parte importante de paternidad centrista.

En resumen, el presente es un argumento/obstáculo instrumental que toma nota de la indefinición de fondo general, en buena medida motivada por la posición nebulosa del partido dominante en el sistema, pero cuyo análisis no revela oposiciones de fondo. Asentado el acuerdo sobre la reforma que es común a los cuatro partidos, por eso se trabaja en la del reglamento de la Cámara Alta —el resto es un puro problema instrumental-. Si no fuera porque el presente funciona como "argumento-pantalla" tras el que se cobijan razones de fondo. El obstáculo no está, pues, en que sea objetivamente difícil el consenso entre los partidos nacionales, sino en las razones que motivan el escaso interés de los mismos en afrontar y resolver el problema.

\section{e) La inviabilidad política de un Senado cuasi-federal}

Éste es el de mayor enjundia, y mejor apariencia, de los obstáculos ficticios a la reforma del Senado. Sentado el hecho, por nadie discutido, que la Cámara Alta coherente con la estructura del Estado realmente existente es un Senado-Cámara territorial, es decir, un Senado cuasi-federal, se viene a sostener que el mismo es inviable por cuanto que la reforma 
constitucional afecta necesariamente el modelo autonómico, le afecta de modo igualitario/homogeneizador, con ello diluye la posición especial de las Comunidades Autónomas "del art. 151" y, en especial, de las "nacionalidades históricas" y, en consecuencia, es inaceptable para los nacionalistas moderados (PNV y CiU) sin cuyo concurso y aceptación la reforma no es políticamente viable. Debe señalarse que ésta es una opinión de difusión doctrinal y periodística, y que se basa en la posición política presunta de las dos citadas formaciones políticas, y que sólo oficiosamente se ha sostenido desde una determinada "sensibilidad" del partido dominante en el sistema.

El argumento de la inaceptabilidad del Senado cuasi-federal para el nacionalismo democrático, es en realidad triple, y se funda en las bien conocidas opiniones de extracción catalanista, que sostiene el señor Pujol, según las cuales, el único federalismo aceptable es el "nacional», es decir, la federación de cuatro Estados: Galicia, Euzkadi (no se sabe si con o sin Navarra), Cataluña (no se sabe bien si incluyendo o no a las Islas y al País Valenciano) y España (es decir, el resto, de habla castellana). El argumento, como he señalado, se desdobla en tres: el federalismo es inaceptable porque homogeneiza y uniformiza las competencias, lo es porque da el mismo status a todas las Comunidades y, finalmente, porque cierra las posibilidades de relación bilateral con el Estado-Poder Central. Debe observarse, antes de proseguir, que el argumento no se refiere para nada al Senado, de modo directo al menos, y que no se basa en posicionamiento oficial alguno de las formaciones políticas citadas.

1) El carácter homogeneizador y uniforme de la representación $y$ las competencias de las Comunidades Autónomas

El subargumento central, sobre el que pivotan los demás, radica en la afirmación de que el federalismo comporta la homogeneización y uniformización de las competencias, y eventualmente de la representación, de las diferentes Comunidades Autónomas, de este modo, se concluye, la reforma del Senado en sentido cuasi-federal resulta inaceptable por uniformizador. Ahora bien, si el supuesto no se da, es decir, si la uniformidad no es inherente a la solución federal, el subargumento se viene a tierra.Y eso exactamente es lo que sucede.

Porque hay que advertir que una solución federal o cuasi-federal no exige per se esa uniformidad. Ni desde el punto de vista material, ni desde el formal. Que no lo supone desde el primero es claro: la asignación general de competencias sobre pesca de bajura, lagos, relaciones con regiones 
fronterizas o idioma propio sólo tiene significado para las Comunidades que, respectivamente, tengan costa, lagos, frontera con otro Estado o idioma propio, por citar sólo algunos ejemplos.Como en nuestro caso hay materias de competencia autónoma que sólo o casi sólo corresponden a un puñado de Comunidades (no hay lagos en el Pais Vasco, ni costa en Extremadura, ni frontera en Rioja, ni lengua propia en Castilla-La Mancha), y, en la mayor parte de los casos la homogeneidad formal supone un apoderamiento de facto superior a las Comunidades "históricas», tal homogeneidad no se puede dar. Pero es que el federalismo no exige, tampoco, la uniformidad competencial formal. Así en los EE.UU. o en la RFA sólo algunos Estados tienen determinadas facultades en política exterior, en el proyecto de "nacionalización" canadiense se contempla un status especial para Quebec, y, si no queremos salir del caso alemán y tenemos memoria, veremos durante el II Reich que Alsacia y Lorena eran parte del Reich pero no Länder del mismo, algunos Estados del Sur de Alemania tenían concordatos particulares con la Iglesia - cosa que, por cierto, aún pervive- y Baviera tuvo nada menos que un Ejército propio hasta 1918 y su propia administración militar hasta 1933. Y ello sin recurrir a la triple lista de Estados ( $A . B$ y C) de la Constitución India o recurrir a figuras exóticas como los EAU o la extinta URSS. La ecuación federalismo=uniformización competencial es, en sentido estricto, una ecuación imaginaria.

La cuestión de la representación en la Cámara es tan obvia que no merece debate, basta ver la composición del Bundestat alemán o austríaco para darse cuenta de ello.

\section{2) La dilución de la especificidad nacionalitaria}

El presente es subargumento que reposa sobre el anterior, pero que no se agota en el mismo. Su diferencia específica radica en la voluntad nacionalista, esa sí rotunda y clara, de mantener su propia especificidad, su "carácter nacional" propio para sí y para las instituciones de autogobierno de sus Comunidades que, en el universo mental nacionalista, reclaman la lealtad política primaria. La cuestión radica en el mantenimiento de un status peculiar y que, en función del mismo, se puedan establecer relaciones políticas bilaterales entre el Gobierno nacional (del Estado) y el Gobierno nacional (de la Comunidad). Obsérvese que, salvado como está el problema de la lengua propia y de su status, la cuestión presente no es tanto un problema de poderes legales cuanto otro de relaciones políticas. Para nadie es un secreto que tanto los nacionalistas catalanes como, en particular, los vascos, han insistido en mantener una relación bilateral con el Gobierno nacional, por la que discurran todas o la mayor parte de las relaciones 
Comunidad Autónoma/Estado-Poder Central. La cuestión radica en si una organización cuasi-federal del Senado constituye obstáculo para el mantenimiento de esas relaciones. La respuesta resulta obvia.

\section{3) El veto de los partidos nacionalistas moderados}

La conclusión propuesta de esta gama de argumentos es la de la existencia de una suerte de veto de los partidos nacionalistas moderados a la reforma del Senado Constitucional, o, más exactamente a la reforma de la Constitución afectante al Senado. Como se ha visto los argumentos presentados no tienen el alcance que de ellos se predica $y$, en buena lógica, no pueden fundamentar la conclusión que se pretende deducir. $Y$ así sucede en el mundo real, la tesis del veto nacionalista no sólo no se confirma, sino que resulta contrafáctica: han sido PNV y CiU, a través de sus grupos parlamentarios en el Senado, los que, junto con IU, han propuesto formalmente la reforma constitucional para convertir al Senado en la Cámara Territorial, al plantearse en el seno de la Comisión de Reglamento la optimización del Senado Constitucional mediante la reforma del Reglamento de la Cámara Alta. El veto preconizado sencillamente no existe.

\section{LOS OBSTÁCULOS VERDADEROS}

La existencia de obstáculos ficticios es, en si misma, indicador de que existen otros, reales, que, por razones diversas o bien no han tenido la relevancia de los anteriores, o bien permanecen en estado latente. De hecho, de la exposición hasta ahora realizada se desprende claramente no sólo su existencia, sino también el contenido propio de alguna o algunas de esas razones subyacentes a las posiciones hostiles a la reforma constitucional afectante al Senado.

De entre los obstáculos que se oponen a la reforma me parece que cuatro son los de mayor relevancia, y lo son no sólo, ni principalmente, por su entidad singular, sino sobre todo por las interacciones que entre ellos operan y que diseñan, en conjunto, un verdadero sistema obstaculizador de potencia nada desdeñable. En breve resumen me parece que tales obstáculos son, en sustancia, cuatro: la defectuosa percepción del instituto de la reforma constitucional por parte de algunas fuerzas políticas, la ausencia de propuestas detalladas y precisas por parte de las mismas, y, en todo caso, el temor derivado del desconocimiento de su impacto sobre 
el funcionamiento del sistema constitucional, el temor a la pérdida del control del proceso y, finalmente, la ausencia de voluntad política de afrontarlo. Toquemos, siquiera sea someramente tales obstáculos.

\section{a) La defectuosa comprensión de la naturaleza de la reforma constitucional}

Buena parte de las principales fuerzas políticas estatales tienen una concepción errónea de la reforma constitucional. Según dicha percepción la reforma se contempla no como un instrumento de corrección de los defectos y de adaptación a los cambios del texto de la Constitución escrita, es decir, no como el instrumento de defensa de la Constitución que por concepción y naturaleza es, sino como un medio de introducir en el tejido institucional una verdadera ruptura, una alteración de las instituciones y orden de valores propios de la Constitución de 1978, con el fin de producir un cambio sustancial de la Constitución misma, con el fin de producir una nueva Constitución. Tarea que, así definida, no sólo no se afronta, sino que se rechaza.

Aunque esa es una percepción en proceso de cambio en los últimos tiempos (en buena medida a causa del debate mismo) la misma se asienta en tres factores de peso no desdeñable: la Historia, la actitud de la derecha constitucional entre 1978 y 1982 , y la naturaleza de la demandas de reforma durante el periodo inicial de la vigencia de la Constitución. Por lo que toca al primer factor hay que tener en cuenta que el fenómeno de la reforma es un suceso casi sin precedentes en nuestra Historia Constitucional, en la que más bien no faltan los casos de utilización del proceso de reforma para procurar cambios sustanciales en la Constitución existente a fin de producir una nueva. Al fin y a la postre eso es lo que se hizo en 1836/37 para sustituir por el texto de 1837 la Constitución de Cádiz; la operación efectuada por los moderados en 1844/45 para sustituir el texto anterior por la Constitución de 1845, y la intentada en 1935 por radicales y cedistas para producir un texto bien distinto al votado por las Constituyentes de 1931. No obstante el ejemplo más claro e influyente es mucho más cercano. ¿Acaso el texto de 1978 no es consecuencia de una "reforma constitucional" de las Leyes Fundamentales del Reino operada por la Ley para la Reforma Política?

Al lado de tales precedentes ¿quién se acuerda del Acta Adicional a la Constitución de 1845, de 1857, y su sucesora la de 1858, de bien breve vigencia? Al lado de esos antecedentes ¿qué fuerza puede temer citar el ejemplo alemán federal, el holandés, etc.? ¿qué fuerza pueden hacer los 
argumentos doctrinales? Con tales antecedentes, en especial los próximos, no es de extrañar que las fuerzas políticas más comprometidas, por razones históricas, con el texto de 1978, y, todo hay que decirlo, las más satisfechas con el mismo en su estado actual -PSOE y CDS-, muestren un profundo recelo ante las propuestas reformistas. $Y$, aunque el problema planteado por la ratificación del Tratado de Maastricht provoque un cambio de percepción ¿quién puede extrañarse que la operación se contemple con recelo?

Por otra parte hay que recordar que aún no se había secado la tinta con la que el texto de 1978 se imprimió, y la derecha constitucional, dividida en torno a la conveniencia del voto al texto constitucional, alzaba ya la bandera de la reforma para proponer dos cambios que, si no suponen una sustitución de la Constitución por otra, no se hallan demasiado lejos, uno afectante al orden constitucional de valores - la eliminación de la proscripción parcial de la pena de muerte - y el otro nada menos que a la estructura del Estado: el Título VIII de la Constitución. En estas condiciones, si la reforma se planteó en su día como algo muy parecido al derribo de una parte significativa del edificio constitucional, nada de particular tiene que los autores de una Constitución, que gráficamente ha definido LUCAS VERDÚ como "resultona", vean con suma suspicacia las propuestas reformistas. Si la derecha constitucional, que nació semi-leal, es reformista es lógico que los leales sean recelosos ante el reformismo. El hecho de que la derecha constitucional haya acabado por hacer suya la Constitución, y de que propuestas de reforma actuales, como la hecha recientemente por el señor Fraga, se muevan en parámetros bien diferentes, no pueden eliminar al respecto cierta prevención.

Tales hechos pueden hacer comprensible que, en materia de política constitucional, los partidos subjetivamente más comprometidos con el texto de 1978 asuman la concepción narvaísta del "gobernar es resistir", y que la cuestión aparezca, a su ojos, envuelta en una nube de recelo no totalmente injustificado que sólo la actuación política responsable puede disipar.

\section{b) La indefinición de la reforma}

Tales efectos deletéreos se ven agravados por uno adicional, que supone per se una acentuación de esos recelos: el considerable grado de indefinición que aqueja a las propuestas reformistas hasta fecha bien reciente. Aquélla incrementa la incertidumbre y con ello hace más gravoso para actores políticos poco dispuestos el asumir cualquier propuesta de 
reforma. Sin embargo, y en contra de lo que pudiera parecer, el mayor factor de incertidumbre no radica primordialmente en el contenido de las propuestas concretas, cuanto en el campo afectado por la reforma. Sin perjuicio de volver inmediatamente sobre esta cuestión, no cabe ocultar, sin embargo, que la falta de una o varias propuesta dotadas del suficiente nivel de detalle, al menos en lo que respecta a las introducidas en sede política, opera por sí sola como un freno, y no sin buenas razones. Sin una propuesta concreta en la mano es difícil hacerse una idea de la envergadura de la reforma propuesta $y$, sobre todo, es difícil calcular el impacto que la misma puede tener sobre los demás órganos constitucionales, sobre el sistema constitucional de relaciones entre los mismos y sobre la delicada trama de hábitos y usos que gira en torno a unos y otras.

No basta, pues, con apuntar las deficiencias, obvias y bien conocidas por los actores políticos, del Senado constitucional, ni basta tampoco solicitar de los mismos posiciones que, a falta de textos objeto de los mismos, tienen que ser necesariamente abstractos. Para producir un posicionamiento serio es imprescindible delinear un proyecto de reforma concreto que pueda ser objeto del mismo, de tal modo que, sin despejar ese factor de incertidumbre es difícil, por no decir imposible, salir del impasse actual, de la política del non movere. De ahí que uno de los signos de la ausencia de voluntad politica de afrontar el problema sea, precisamente, la falta de propuestas concretas por parte de los actores políticos, ausencia que, por sí sola, basta para bloquear el proceso.

\section{c) El temor al desmandamiento del proceso de reforma}

O lo que, humorísticamente, podríamos llamar "el síndrome del melón". En otras palabras, tanto o más que la incertidumbre producida por la falta de pronunciamientos concretos por parte de los actores políticos, lo que opera como un freno poderosísimo a la reforma es el temor de todos los actores políticos a que, una vez abierto el proceso de reforma, fuere difícilmente previsible el resultado del mismo, el temor a que la reforma, una vez haya tomado estado oficial, se vea desbordada por las demandas de modificaciones afectantes a materias que vayan más allá de la solución del doble problema de la participación de las Autonomías en la formación de la voluntad del Estado y la correspondiente modificación de la Cámara Alta. Y a que, con la presencia de tales demandas ante la opinión pública, el proceso escape al control de los partidos del arco constitucional.

Tal temor puede parecer irracional o infundado, pero es, desde lue- 
go, un freno importantísimo para cualquier cambio en el texto de 1978, y es ese temor el que da racionalidad a la polémica, por lo demás un tanto absurda, que hemos presenciado en torno a la necesidad o no de la reforma para poder ratificar el Tratado de Unión Europea. Reconozcamos que el temor no carece de fundamento, basta pensar en los antedecentes de la derecha constitucional, o en la imprevisible actitud de las formaciones nacionalista o regionalistas menores o radicales $y$ su impacto sobre PNV y $\mathrm{CiU}$, o en la posibilidad de que estas formaciones planteen como condición para su participación en el consenso modificaciones afectantes al Título VIII, como la reaparición del problema de la reintegración foral y los derechos históricos, las recientes demandas de Administración única o la cuestión del estatuto constitucional de la provincia y de sus órganos de gobierno, pongamos por caso.

Como los actores políticos tienen asumido que la reforma constitucional requiere un consenso muy amplio $y$, en todo caso, tan amplio como el recibido por la redacción original del texto de 1978 y/o los Estatutos de Autonomía, esa incertidumbre bloquea cualquier paso adelante. En otras palabras, el acuerdo sobre qué preceptos de la Constitución no se deben tocar en ningún caso es la condición previa, el prerrequisito absoluto, para la viabilidad de cualquier operación de reforma afectante al Senado constitucional. Va de suyo que la indefinición, o el no pronunciamiento de los partidos subjetivamente más comprometidos con el texto constitucional, constituye, por sí solo, el principal problema desde el punto de vista de la política constitucional.

\section{d) La ausencia de voluntad política}

Con lo cual llegamos a la causa causarum: la ausencia de voluntad política de afrontar la reforma, que afecta principalmente a los partidos nacionales $y$, entre ellos, especialmente, a los citados PSOE y CDS. Dos son los factores principales de esa ausencia: la incertidumbre y la comodidad. La incertidumbre ya ha sido señalada y brevemente analizada, queda la última, la comodidad. $Y$ es que el Senado constitucional puede que no sea una institución satisfactoria desde el punto de vista de la organización del Parlamento, como no lo es, indudablemente, desde el punto de vista de la estructura del Estado realmente existente, pero eso no significa que carezca de ventajas. Las tiene y muchas, pero éstas pueden resumirse en una: el Senado constitucional es una institución cómoda para el Gobierno, para el Congreso de los Diputados y para los estados mayores de los partidos nacionales. 


\section{1) Un Senado cómodo para el Gobierno}

En primer lugar el Senado constitucional es una institución cómoda para el Gobierno. Es lógico que sea así, puesto que el actual no es más que el heredero devaluado del Senado de la LRP y éste se diseñó, inteligentemente por cierto, para operar como Cámara de apoyo o respaldo al Gobierno, especialmente para el caso de que éste quedara en minoría en la Cámara Baja del Parlamento. No es en modo alguno casual que el Gobierno, sea el que sea, siempre haya tenido mayoría en el Senado, aun no teniéndola en el Congreso. El Senado constitucional obedece casi a la misma composición y método de elección que su predecesor, el Senado LRP, siendo la única variante la sustitución de los senadores reales por los autonómicos, nada de particular tiene que su composición política obedezca al mismo patrón; una versión corregida en sentido mayoritario de la del Congreso, en la que la corrección favorece a los dos partidos más votados, especialmente a aquel que predomine en las provincias con población inferior a la media que, feliz casualidad, ha sido siempre el del Gobierno.Y si la composición política obedece al mismo patrón resulta lógico pensar que la actitud de la Cámara haya sido siempre la misma: el respaldo al Gobierno.

Es cierto que el Senado constitucional es menos racional que el de la LRP, por cuanto la disminución de sus poderes impide que el Gobierno pueda utilizar a la Cámara Alta para bloquear los proyectos que estime a la vez inevitables e indeseables, y debilita la significación política del apoyo que puede obtener de la confianza del Senado. Pero no es menos cierto que el que haya menos ron y más coca-cola en el vaso no altera la naturaleza de su contenido. Cualquier modificación de la composición introduciría un factor de incertidumbre, el Senado de las Autonomías, vinculado a la elección de los Parlamentos de éstas no garantiza una composición politica similar, y, con ello, despoja de aquel sentido a la Cámara Alta, como el cambio de la composición sólo tiene sentido si, con ella, se modifican los poderes del Senado, y esa modificación pasa por algún tipo de reforzamiento de los mismos se deduce claramente que cualquier Senado alternativo es, aquí y ahora, menos cómodo que el actual para el Gobierno. Nada de particular tiene que éste tienda a adoptar en la cuestión la política torie sobre la Cámara de los Lores: la actual es la mejor de las Cámaras Altas posibles.

\section{2) Un Senado cómodo para el Congreso}

Si el actual es un Senado cómodo para el Gobierno no lo es menos 
para el Congreso. El actual es una Cámara de segunda lectura políticamente subordinado a la Cámara Baja. La mayoría existente en ésta no sólo puede superar fácilmente la oposición de la mayoría senatorial, sino que, además puede, si lo desea, destruir la no desdeñable influencia que el Senado ejerce hoy en la producción legislativa. La ordenación de los poderes de ambas Cámaras y sus relaciones configura al Senado como una asamblea subordinada - su confianza no es necesaria para gobernar- y por ende; su control de la acción de gobierno es necesariamente más reducida -y dependiente-, el Congreso puede ignorar la voz del Senado en la producción legislativa al tener la palabra al tiempo primera y última sobre los proyecto de ley. En consecuencia, cualquier reforma - sea cual fuereque dé mayor autoridad, o mayores poderes, o ambas cosas, al Senado será acogida con recelo por un Congreso al que esa reforma le elevará un competidor potencial por la atención pública y por el poder mucho más fuerte que el Senado actual. El medio ambiente en la Carrera de S. Jerónimo nunca ha sido favorable a la Plaza de la Marina, y, en razón de ello, los diputados tienden al quieta non movere en la cuestión que tratamos.

Para el Congreso la mejor opción es la unicameral, que no haya Senado, pero si lo hay que sea lo menos Parlamento posible, como es difícil pensar una Cámara más débil que el Senado actual en sus relaciones con el Congreso, éste último, por naturaleza inclinado a una actitud minimalista, en condiciones normales se inclinará por dejar las cosas como están, o por una reforma minimalista, la muy reciente propuesta del señor Fraga es, en este sentido, modélica. Y conviene no olvidar que en el Congreso se sientan tanto los líderes políticos, como la mayor parte de los estados mayores de los partidos sin cuyo concurso la reforma carece de viabilidad.

\section{3) Un Senado cómodo para las cúpulas partidistas}

Si el Senado constitucional es cómodo para Gobierno y Congreso, y los dirigentes partidarios nacionales se sientan en él va de suyo el porqué el Senado minimalista actual resulta cómodo para las cúpulas partidistas (y porqué en su elección se mantienen las listas abiertas, si se me permite la maldad). Un Senado con mayor autoridad, o con mayores poderes, o con ambas cosas reducirá el protagonismo -obligará a compartir una parte del protagonismo- a los señores diputados, especialmente a ciertos señores diputados, lo que difícilmente puede ser plato de gusto. So pena de cambiar la política de personal parlamentario. Cuestión que conviene tratar aquí.

Porque una de las virtualidades rara vez señaladas es que el Senado 
constitucional constituye un recurso no despreciable en la política de personal de los partidos parlamentarios. La Cámara Alta es útil al respecto por cuatro motivos distintos, todos ellos ligados al control central de las listas electorales, en primer lugar, el Senado es empleado como pista de pruebas de parlamentarios, lugar de formación de miembros de las Cámaras, $y$, en consecuencia, cantera de extracción de parlamentarios probados que, con posterioridad, acceden (ascienden) al Congreso, los ejemplos no son escasos ciertamente; en segundo lugar, la Cámara Alta proporciona un medio cómodo para sostener con cargo a fondos públicos personal directivo de los partidos, cuya actividad parlamentaria es cuasi nula o sencillamente inexistente, actividad en la que es maestro el partido dominante actual; en tercer lugar la Cámara Alta proporciona un fondo de escaños de elección en general fácilmente predecible con el que operar para dulcificar la siempre dolorosa y en no pocos casos conflictiva operación de elaboración de listas electorales; finalmente el Senado opera como Cámara de jubilación anticipada o de premio a los cuadros medios cuya presencia no es posible o deseable en las listas del Congreso. Va de suyo que, en estas condiciones, pretender de los partidos que alteren su política de personal y desplacen personalidades notables al Senado como medio de potenciar éste resulta un pío deseo, que no es propio de este mundo. Si se desea que los partidos cambien esa política de personal hay que cambiar las condiciones que hacen racional la actualmente seguida.

Las excepciones a esta política de personal son más frecuentes en los senadores de extracción autonómica. $Y$ ello por dos motivos: de un lado, porque en general el control central de las candidaturas es más laxo, - la influencia local más fuerte, en el caso de los senadores autonómicos, si a ello agregamos que su elección es independiente o no simultánea con la del Congreso se hace más difícil su uso como cámara de compensación; del otro, porque la elección como senador autonómico se plantea y percibe como un ascenso desde la condición de particular o desde la de parlamentario autonómico, y por ende es más fácil el reclutamiento de personal con mayor peso político, como acredita la frecuencia de portavoces de los Parlamentos autónomos que osteritan, al tiempo, la condición de senador. Gracias a Dios tales senadores son una pequeña minoría.

\section{e) La hostilidad a la potenciación del Senado}

En estas condiciones nada tiene de extraño que los partidos, en especial los aparatos centrales de los partidos nacionales -elementos dominantes en un sistema de partidos caracterizado por cuasi-monopolio de los partidos de electores-, hayan desarrollado una actitud reticente, cuando 
no hostil, a cualquier tipo de potenciación del Senado. Seamos realistas, todo les mueve a ello. Una reforma del Senado que aumente la importancia política del mismo limitará o pondrá fin a la política de personal predominante - lo que aumentará los costes de la confección de las listas del Congreso-, tenderá a potenciar la Cámara Alta y convertirá a la misma en un competidor más serio por el poder y la imagen que el Congreso - competidor tanto más serio cuanto que la tradición senatorial registra una más elevada cortesía parlamentaria, una menor tensión interpartidaria, y una mayor facilidad de las prácticas consensuales- obligará a generar un liderazgo parlamentario diferente y competidor potencial del liderazgo parlamentario en el Congreso, aumentará la complejidad del proceso político y lo hará menos manejable para el Gobierno, etc. En una palabra, obligará a repartir juego y compartir poder, tanto al Gobierno, como al Congreso, como a los lideres partidarios y sus estados mayores. No faltan razones para la reticencia, aunque éstas no sean las publicitadas.

Sin embargo, el que posiblemente es uno de los motivos de hostilidad latente más fuerte cabe buscarlo en el problema del reclutamiento del personal. Como a nadie se le oculta, la conversión del Senado en Cámara Territorial exige un reclutamiento si no exclusivo, sí predominante de los senadores en términos similares a los actuales "autonómicos". Amén de exigir la supresión de ese donoso disparate que es la posibilidad de disolución de la Cámara Alta. Tal escenario comporta una Cámara Alta con mayores poderes en cuyo reclutamiento es más fuerte la posición de los cuadros regionales de los partidos estatales, en especial de aquellos que están en el gobierno autónomo. Lo que comportaría tres consecuencias: una mayor influencia de las organizaciones territoriales de los partidos en el proceso político, una cierta federalización del reclutamiento de los parlamentarios y de la propia composición de la Cámara, en detrimento del poder de la Dirección Nacional, un robustecimiento de la posición política de los "barones" y los "califas" al facilitar una composición de la Cámara determinada en mayor grado por éstos que por la Dirección Nacional. Y el espectro de una Cámara en la que la fuerte influencia de los Josés, los Manueles o los Joanes confluya con la de los Jordis, aunque indudablemente permitirá una mejor solución al crónico problema de la participación de las Comunidades en la formación de la voluntad del Estado en general y de las decisiones afectantes a las materias compartidas en particular, no constituye ciertamente el más agradable de los sueños para las Direcciones Nacionales de los partidos estatales. Su encendido entusiasmo por la solución del problema es, pues, fácilmente comprensible. 


\section{NOTA BIBLIOGRÁFICA}

Para el Senado de la LRP la cita obligada es la P. LUCAS VeRdú: La octava ley fundamental. Madrid, 1976. La configuración del Senado constitucional es un tema recurrente en la bibliografía de F. FERNÁNDEZ SEGADO, por todos vide: "La Construcción del Senado en el proceso constituyente", $R E P$, n. ${ }^{\circ} 38$, 1984, págs. 63 y ss.; asimismo pueden verse J. CAPO GIOL: «El debate sobre el bicameralismo: la Cámara denominada de representación territorial", en VV.AA.: Parlamento y Sociedad Civil. Barcelona, 1980, páginas 283 y ss., y R. PUNSET: El Senado y las Comunidades Autónomas. Madrid, Tecnos, 1987, passim. De interés asimismo R.L. CHUECA Rodríguez: "Teoría y práctica del bicameralismo en la Constitución española", REDC, n. ${ }^{\circ}$ 10, Madrid, 1984, págs. 76 y ss. El punto de vista según el cual el Senado tiene como función latente una de índole conservadora puede verse, entre otros, en J. J. Solozábal EchavarRía: "Alcance jurídico de las cláusulas definitorias constitucionales", REDC, n. ${ }^{\circ} 15$, Madrid, 1985, pág. 81. Sobre los problemas de la reforma constitucional, las referencias imprescindibles son de P. de VeGA: La reforma constitucional, Madrid, Tecnos, 1986; J. Pérez Royo: La reforma de la Constitución. Madrid, C. de los D, 1987. Una toma de posición sugerente en J. PÉREZ RoYo: "La reforma imposible", en Claves de razón práctica, n. ${ }^{\circ} 20$, Madrid, 1992, págs. 9 y ss. La exposición clásica de la reforma manipulativa del reglamento en TORNOS MÁs et alii: Informe sobre las autonomías. Madrid, Civitas, 1988 (hay edición anterior, Barcelona, 1987). He expuesto mi posición de modo detallado en una monografía, M. MARTínez SOSPEDRA: La reforma del Senado. Valencia, Fundación Universitaria S. Pablo-CEU, 1990. 